\title{
What's a term? An attempt to define the term within the theoretical framework of text linguistics
}

\author{
Tanja Collet \\ University of Windsor
}

In texts for specific purposes, terms adopt a behaviour which is contrary to the prescriptive demands of traditional terminology. Indeed, they exhibit variability both on the level of their meaning content and on the level of their linear structure. Their meaning contents are not fixed, but may be changed by the language user's verbal and non-verbal activities. Their linear structures are not fixed, but can be adjusted to the characteristics of their linguistic environment, specifically the sentence or sequence of sentences in which they are being used. Examined within the framework of text linguistics, it becomes clear that this variability contributes to two basic characteristics of any body of sentences which constitutes a text, namely text coherence and text cohesion. Consequently, the aim of this article is to propose a new definition of the term, a definition which underscores the role the term plays in bringing about texture in texts for specific purposes.

\section{Introduction}

The purpose of this article is to define 'the term' within the theoretical framework of text linguistics, a framework largely neglected by traditional terminology, i.e. the school of thought loyal to the principles formulated by Eugen Wüster (1979), the dominant voice of the Vienna school, as well as by Russian terminologists, like D.S. Lotte (1981). The article is divided as follows. In section 1, the need for a textlinguistic approach to the term is illustrated by identifying aspects of the theory of the term, ascribed to by traditional terminology, and which cannot be validated by empirical data collected in texts for specific purposes. In section 2, the nature of these texts for specific purposes is described in more detail. In section 3, the behavior of the term in texts for specific purposes is analyzed. It will be shown that a term has at least two fundamental functions in a text for specific purposes. On the one hand, its presence in the text allows for the creation of a link with an entity of the non-textual world, i.e. the world which exists outside of the text but to which the text refers. On the other hand, its presence allows for the construction of a semantic edifice within the text through the creation of coreferential chains which strengthen the overall unity of the text. These two functions, i.e. the naming function of the term as well as its cohesion producing function, lead to a behavior in specialized discourse which does not coincide with the theory of the term put forward by traditional termino- 
logy. Finally, in section 4, a new definition of the term will be proposed. This definition will encompass both functions of the term, i.e. its naming function as well as its cohesion producing function. It will emphasize the term's original and dynamic contribution to text cohesion and to text coherence.

\section{The textlinguistic approach and traditional terminology}

Traditional terminology approaches the term from a viewpoint that has undoubtedly hindered a truly fact-based study of the term, namely the standardization of the vocabulary of languages for special purposes. This objective has its roots in the positivist belief that natural language possesses characteristics which are likely to constitute an impediment to clear and precise communication. This conviction led to a working method and to a theory of the term, which terminologists began to question at least a decade ago and continue to criticize today. Indeed, it is felt by many terminologists (Sager 1990; Boulanger 1995; Bowker 1998; Bourigault and Slodzian 1999; Temmerman 2000, to name a few) that traditional terminology largely disregards the facts of special language communication as they can be observed in texts for specific purposes, and instead tries to impose on the term a number of features and thus also a behavior in specialized discourse.

Traditional terminology requires that any terminological undertaking have as its starting point a concept or a system of concepts. Within traditional terminology concepts are regarded as language-independent entities, i.e. as entities that take shape and exist outside of language. Terms, i.e. objects that are formed and exist within a language, have to be assigned to these concepts, preferably in a permanent manner. The permanent assignment of a term to a concept has to respect a number of principles, which are deemed necessary to ensure that specialized discourse remains devoid of ambiguity. One of these principles is the wellknown principle of univocity, according to which a concept can only be named by one term and a term can only refer to one concept.

The goal of these tenets is to equip the term with a number of features, which are to yield the required behavior in discourse, i.e. a behavior that does not inject in the text any undesirable effects that might result in ambiguity or a lack of precision. Two of these features need to be examined here. They have to do with the meaning content of the term on the one hand, and with its linear structure on the other.

Firstly, if the meaning of a term is a language-independent concept, it follows that the term is a context-independent lexical item, i.e. a lexical item that always conveys the same meaning whatever the linguistic context in which it is employed.

Le contenu notionnel d'un terme est déterminé par la notion que ce terme désigne; la signification [...] ne peut pas dépendre de la phrase dans laquelle le terme est employé, elle doit être déterminée par le système de notions tout 
entier et par la terminologie de la discipline donnée du domaine du savoir en question. (Lotte 1981: 6-7)

If true, the term would be a lexical item unlike any other. Indeed, contrary to the meaning of an ordinary word, the term's meaning would not accept or permit any alteration, however small, of its content in discourse. A common characteristic of natural language, namely the meaning evolution which often leads to polysemy in language for general purposes, would thus be absent from specialized communication, as a scientist or researcher would not be able to adjust the meaning content of an existing term to advances, for instance, in the theoretical sphere. As a matter of fact, the exercise being carried out in this article, which is to redefine the concept at the core of any terminological study, namely the concept 'term', would be hampered by the fact that the word form term would refer to a concept that can only be named by a linguistic object. Its content, on the other hand, would be outside the reach of language, as concepts supposedly exist in a world outside language that is objectively given, i.e. that is independent of human experience as expressed through language. Stated otherwise, it would be impossible or in any case very difficult to renegotiate the meaning content of a term in discourse. Research carried out by Temmerman (1997) on the terminology of the life sciences, however, has shown that terms do undergo the polysemous meaning evolution which tends to accompany changes in the human understanding of a phenomenon. Her analysis (Temmerman 1997: 67-77) of the evolution of the meaning of the term 'cloning' and of the resultant highly polysemous nature of this term is a case in point.

Secondly, if a term is assigned to a language-independent concept on a permanent basis, it follows that the term is a label, i.e. a linguistic object that is so static that it refuses any modification of its relationship to this concept, even if this modification only concerns its linear structure.

Structurally, terms tend to fall into at least two categories. They are either single-word units, like antenna, reflector, lens, etc., or multiword units, like aperture antenna, beam width, multiple beam antenna, etc. The latter category consists mainly of complex terms, which generally possess the form of a noun phrase without the initial slot for a determiner. Contrary to single-word terms, which exhibit syntactic atomicity (Di Sciullo and Williams 1987), these complex terms exhibit syntactic transparency (Di Sciullo and Williams 1987): their linear structure is accessible to the rules of phrasal syntax, for instance to the rules governing ellipsis or reduction.

The alleged static label-like nature of the term is alluded to by Lotte (1981: 6-7) in the paragraph already quoted above, when he states that not only the meaning of the term but "(la forme et la construction syntaxique aussi [the emphasis is mine]) ne peut pas dépendre de la phrase dans laquelle le terme est employé." If true, the term's structure 
would always remain the same. It would not, for instance, change from one occurrence to the next in a sequence of sentences within a text or from one occurrence to the next in a body of texts.

My own research (Collet 2000 and 2003), however, into the behavioral patterns of terms in specialized discourse has shown that terms, especially syntactically transparent complex terms, do adapt their structure to the characteristics of the sentences in which they appear. One of the ways in which these complex terms adjust their structure to their sentential environment is by allowing that one or more of their constituents be zeroed under certain circumstances. These circumstances are the following:

1) the term is reiterated, i.e. it recurs at least once in the sentence or in a sequence of sentences; and/or

2) the sentence contains lexical items similar in form and/or meaning to one or more constituents of the term;

3 ) the informativity (de Beaugrande and Dressler 1986) of the term or of some of its constituents is reduced by circumstances (1) and/or (2) and can only be restored by altering the form of the reiterated term, i.e. by having the same content recur but with a different form;

4) the constituents deleted because of circumstance (3) can be reconstructed from the environment, i.e. in situ. Indeed, as pointed out by Harris (1991:84), a deleted constituent can be reconstructed since "we can say that the choice [of the absent constituent or symbol] had been made (by virtue of the environing symbols) but zeroed - i.e. its physical shape is zero, so that it cannot be seen except by inference from the environment".

Circumstances (1) to (4) generally lead to the simultaneous presence in a sentence or in a sequence of sentences of several forms of the same term. This can be observed in the excerpt below.

The 'separation adapter' was bolted to the Titan III - C [launch vehicle] and provided the mounting for ATS - 6 [Applications Technology Satellite] at each of the four corners of the EVM [earth viewing module]. The 'adapter' also provided the pyrotechnic release mechanism and springs to separate the spacecraft from the launch vehicle. (Wales 1981: 21)

Since the tenets put forward by traditional terminology do not equip the term with features that result in the required behaviour in discourse, it can be concluded that these tenets are not borne out by empirical data. Consequently, there is a need for a theory of the term that respects the facts of special language communication, thus for a theory that is empirically adequate. A useful framework for such a theory is text linguistics. Indeed, text linguistics seems especially suitable as the text is the term's natural habitat and as the data gathered in this habitat contradict the traditional theory. 
Appeals for a text linguistic approach to the study of the term are not new. Bourigault and Slodzian, for instance, citing the prevailing corpus-based nature of terminology practice today as well as the inadequacy, in such an environment, of a prescriptive and purely onomasiological approach to the term, made such an appeal in 1999:

L'ensemble de ces constats empiriques entraîne des changements en profondeur de la pratique terminologique: l'activité de construction d'une terminologie est désormais essentiellement une tâche d'analyse de corpus textuels. Ils appellent du même coup à un renouvellement théorique de la terminologie: c'est dans le cadre d'une linguistique textuelle [the emphasis is mine] que doivent être posées les bases théoriques de la terminologie. (Bourigault and Slodzian 1999: 30)

Bourigault and Slodzian did not, however, redefine the term. The present study, on the other hand, attempts to apply textlinguistic concepts towards a definition of the term.

This attempt also reaffirms the link between terminology and LSP (Language for Special Purposes) research. This applied linguistic field traditionally concentrated its analyses on the lexical and syntactical features of special languages but presently tries to go beyond the level of the sentence. Consequently, LSP research has seen in recent years, according to Schröder (1991: 1), "an increasing influence of [...] textlinguistic approaches upon the research of special texts [...]."

\section{Text linguistics and texts for specific purposes}

Text linguistics, which emerged in the 1960s, broke with the dominant structuralist approach to the study of language in at least two ways. Firstly, it maintained that studying real language, i.e. parole, and not abstract language, i.e. langue, is the best way to understand the true nature of language. Secondly, it maintained that meaningful research into the nature of language could be undertaken beyond the level of the sentence, which was then generally considered as constituting the largest unit of linguistic research.

Today, text linguistics approaches the study of the level of the text from at least three different perspectives. These are (1) the text itself, which is seen as the product of a communicative act or event, (2) the participants in the communicative event, i.e. the producer and the receiver of the text, and (3) the situation in which the communicative event takes places. For the purposes of this article, only the first of these three perspectives will be considered. Within this perspective, the text is a construct that has to have texture, i.e. it has to possess characteristics that allow it to function as a unit. At least two such characteristics have been identified.

The first characteristic, named coherence, subsumes the means for connecting ideas or meanings or concepts. Coherence is generally consid- 
ered as a property which is not inherent in a text but which is assigned to it by the receiver upon interpretation of the text.

I do not consider [...] coherence as an inherent property of a verbal object, I believe rather that it is a property assigned (or not assigned) to a verbal object, in whatever form, in a special context by an interpreter. (Petöfi 1983: 266)

The receiver, for instance the reader of a text, is thought to use 'background' knowledge during the interpretation process of a text. This knowledge encompasses beliefs and assumptions about the world as well as language-related knowledge, i.e. knowledge about grammar and about words and their meanings but also knowledge about how texts function. These two sorts of knowledge, world-related and language-related, help the receiver to create correlates between the text and the world outside the text to which the text refers. If the receiver is successful in establishing these correlates, the text is deemed coherent, and thus interpretable for the receiver.

The second characteristic, named cohesion, subsumes the means for connecting units, i.e. words, word groups, clauses and sentences, within a text in order to ensure the flow of information from one point to the next.

The term COHESION is used [...] for the relations obtaining among the sentences and clauses of a text. These relations, which occur on the grammatic stratum, are signaled by certain grammatical and lexical features reflecting discourse structure on a higher, semologic stratum. These features, such as anaphora [...] are called COHESIVE. They account for what may also be referred to as the textual connectivity of sentences and clauses. They do not by themselves constitute cohesion but they mark which clauses and sentences are related and in what manner. This relatedness of clauses and sentences constitutes the internal cohesion of a text. (Gutwinski 1976: 26)

Contrary to coherence, which is "the result of a subjective, knowledgebased interpretation" (Lundquist 1989: 122) of a text by its recei-ver, cohesion is an inherent, i.e. a given property of the text. Indeed, it is a property created with grammatical and/or lexical means during the writing of any text by its producer. As Gutwinski (1976: 33) points out: "texts may display stronger or weaker cohesion but there will be no texts without cohesion [since] anything which is a text has cohesion." The absence of cohesion would, in fact, signal that the sentences seemingly grouped together in a text are not connected, and thus constitute a set of discrete, i.e. separate utterances.

These two properties, coherence and cohesion, give texture to any text, be it a text written in language for general purposes (LGP), or a subject-oriented text written in language for special purposes. Hoffmann (1987: 300) defines the subject-oriented or special text as follows: 
A 'special' text is an instrument and, at the same time, the result of a communicative act carried out in connection with or with respect to a specialized social or individual activity. It constitutes a structural and functional unit (whole) and consists of a finite, ordered set of pragmatically, semantically, and syntactically 'coherent/cohesive sentences/utterances' [the emphasis is mine] (textemes), which, being complex language signs, correspond to complex propositions in human thinking and to complex states of affairs in objective reality.

To create texture, coherence and cohesion both rely on lexical means, more precisely on content words which have a strong lexical instead of a grammatical meaning. Consequently, a textlinguistic approach to the study of the term needs to account for the role terms play in the creation of these two properties of the text, the environment in which terms are not only used but in which their forms can be constructed and their meaning content delineated.

\section{Term behavior in texts for specific purposes}

Terms, like words, can be described simply as consisting of a linear structure which is semantically charged, i.e. which conveys meaning. They are, however, different from 'ordinary' words in at least two ways. Firstly, an overwhelming proportion of terms are complex and exhibit syntactic transparency. Statistics obtained by Cajolet-Laganière and Martel (1994) for French texts for specific purposes indicate, for instance, that on average only $38 \%$ of all the terms used in these texts are single-word units. Secondly, terms convey meanings that are highly technical or scientific in nature. Indeed, they generally refer to concrete or abstract realities in the world outside language or outside the text, the full understanding of which requires expert knowledge.

In texts for specific purposes, both the linear structure and the meaning content of the term play an important and dynamic part in the creation of texture. More particularly, the linear structure of the term can be used in ways that lead to text cohesion, whereas the meaning content of the term is crucial for the bringing about of text coherence.

\subsection{Text coherence and naming function of the term}

As explained above, text coherence is established during the reading or interpretation process, when the receiver of the text tries to connect what is mentioned in the text to correlates in the world outside the text. The meaning content of the term is of great importance during this process, as it is part of the language-related 'background' knowledge the receiver uses to establish these correlates. 
The term is a content word, and thus a linguistic object that stands for a concrete or abstract reality in the world outside language, which it names. When used in a text, the term does not only point to the concrete or abstract reality it represents but also activates in the mind of the receiver knowledge about this reality. The knowledge that is so brought to the surface corresponds to the meaning content of the term. In this regard, it is difficult to distinguish between purely language-related knowledge as opposed to world-related knowledge, or between what was traditionally called semantic knowledge, which was considered fixed or at least fixable, and encyclopaedic knowledge. A dynamic semantics, as proposed by Eikmeyer and Rieser (1981), seems more appropriate to capture the nature of the meaning content of the term. Indeed, it allows for meaning to be variable: "meanings are not fixed objects of any sort, they are fuzzy, flexible and open to adjustment." (Eikmeyer and Rieser 1981: 135) As for the term, its meaning content can vary in at least two ways, namely laterally, from language user to language user, and vertically, i.e. in time. Indeed, the meaning content of an apparently semantically transparent term, like single conversion repeater, is likely to vary depending on whether the user is a telecommunications expert or not. The expert's meaning content is in all probability richer than the non-expert's. The latter, for instance, might have a meaning content which only partially coincides with what the term refers to: "a satellite repeater which translates the received up-link signal directly to the lower down-link frequency band for amplification and retransmission" (Lauriston and Le Néal 1985: 254). In addition, the meaning content of a term also evolves over time or, as Eikmeyer and Rieser (1981: 135) put it, "may be continuously changed by people's verbal or non-verbal activities." The expert's meaning content, for instance, may change when his research activities uncover something new.

This variability accounts for differences in the assignment of coherence to the same text by different readers or by the same reader at different moments in time. The excerpt below, for instance, taken from a textbook on satellite communications, is in all likelihood fully coherent for its two producers or for other telecommunications experts. These receivers, when confronted with the terms this excerpt contains (filter, transponder, intermodulation product, amplitude, phase ripple and pass band), have at their disposal detailed meaning contents for each term which allow them to establish solid correlates between this text fragment and the outside world. For the engineering student, however, who is still being initiated into the field, the excerpt's coherence may be weaker, depending on the nature of the meaning content he possesses for each term. Finally, for the layperson, the excerpt may be almost incoherent, as the terms fail to activate in his mind meaning contents strong enough to link the text fragment to the outside language realities. In all three of these situations, the terms name the same abstract or concrete realities but convey meanings to the text's receivers that are different in nature. 
Stringent requirements are placed on the filters used in transponders, since they must provide good rejection of unwanted frequencies, such as intermodulation products, and also have very low amplitude and phase ripple in their pass bands. (Bostian and Pratt 1986: 76)

Alternatively, the excerpt above may become more coherent (or less coherent) for a reader over time as the meaning contents he possesses for the terms in the excerpt change. Here as well, the terms continue to name the same realities but their meaning content changes, i.e. becomes stronger (or weaker).

It is this 'vertical' and 'lateral' variability of the term's meaning content that makes the current exercise possible, i.e. that allows the producer of this text to adjust the meaning content of the term 'term' to the results of her "verbal and non-verbal activities," and thus also to distinguish it from the meaning contents other terminologists may have. Consequently, it is also this feature of the term's meaning content that can lead to the polysemy observed by Temmerman (1997). Indeed, the meaning content, given to the term 'term' in this text, and which could be represented as 'term ${ }_{z}$, differs from the meaning content, 'term ${ }_{x}$, the late Eugen Wüster (1979) assigned to it, for instance.

\subsection{Text cohesion and cohesion producing function of the term}

Texts, as indicated above, exhibit connectivity, i.e. cohesion. They are made up of a set of connected text fragments. These connections allow meaning to pass from one text fragment to another, thus establishing coreferential chains within the text, i.e. chains of text fragments that refer to the same concrete or abstract reality. These connected text fragments, which are in fact "various types of word-recurrence" (Harris 1982: 233), can be obtained with grammatical or with lexical means. Grammatical means, which allow the meaning contents of a word to recur in a clause or sentence, are for instance anaphora as well as ellipses. Among the lexical means can be listed lexical repetitions and also lexical variations. Lexical repetitions simply repeat a word or word group as it is in another clause or sentence, whereas lexical variations use a variant instead. Variants typically consist of synonyms or hyperonyms, i.e. of words or word groups that ensure the recurrence of the meaning contents of another word or word group. However, as argued in Collet (2004), variants can also be different forms of the same word or word group, i.e. for instance forms, like adapter for separation adapter, obtained through reduction or constituent deletion.

In texts for specific purposes, terms contribute to text cohesion in all manners, grammatical or lexical, described. Indeed, not unlike 'ordinary' texts, texts for specific purposes contain coreferential chains made up of a term and a pronoun (in which case the term is the antecedent of the pronoun that refers back to it anaphorically), or of a term and a lexi- 
cal repetition or a lexical variant, such as a synonym or a hyperonym. The excerpts below illustrate these various sorts of word-recurrence, which are of course to be expected in any text, subject-oriented or not.

The purpose of the antennae $[\ldots]$ is to receive the signal ${ }^{\mathrm{i}}$ from space, feed the signali to the transponder, and then retransmit iti. (Bleazard 1985: 29)

Flat panel solar arraysi provide a more efficient configuration, but also introduce additional complications. First of all, the solar sails $\mathrm{i}$ may each have a length of 30 feet or more and must be stored in a folded-up position during the launch stage. (Bleazard 1985: 119)

[...] a single solid motor can be integrated into the spacecraft ${ }^{\mathrm{i}}$ and the empty case carried for the remainder of the satellite ${ }^{i}$ lifetime after firing. (Elbert 1987: 204)

Subject-oriented texts, however, also display a more unusual pattern of word-recurrence. This pattern, which is relatively widespread in texts for specific purposes, is directly linked to the presence in these texts of an exceptionally large amount of terms exhibiting syntactic transparency. As explained in section 2 above, constituents of the linear structures of these terms can be zeroed under certain circumstances, the principal circumstance being the need to reuse the term. As a result, texts for specific purposes feature coreferential chains, which are quite unique in that they link two or more forms of the same term, as in the excerpt below.

[...] the solar sails may each have a length of 30 feet or more and must be stored in a folded-up position during the launch stage. When the satellite reaches geostationary orbit they are then opened in a concertina fashion to their fullest extent. Also, a mechanism is required to ensure that the arrays are always pointing directly at the sun so that they receive maximum incident illumination. This is achieved by positioning sun sensors on the sails ${ }^{1}$. (Bleazard 1985: 119)

In view of this, I have argued elsewhere (Collet 2000, for instance) that complex terms exhibiting syntactic transparency are, in fact, paradigms, i.e. closed sets composed of the full-length form of the term and of all its alternate shorter forms. In subject-oriented texts, these paradigms become a means for constructing coreferential chains, and thus constitute a unique way of achieving text cohesion.

\section{Consequences for a definition of the term}

In texts for specific purposes, the term, a semantically charged linear structure, exhibits variability on the level of both its meaning contentand of its linear structure. Traditional terminology finds itself at odds with 
these phenomena, since its prescriptive approach makes opposite demands of the term. The textlinguistic approach proposed in this article is able to account for this variability. Indeed, it reveals a link between the term's behaviour and the conditions necessary for a set of sentences to be a text. In a subject-oriented text, it seems, the term is more than just a label, the name of an abstract or concrete reality; it becomes a means for achieving texture. Firstly, its meaning content, which can vary laterally and vertically, allows readers of a text to establish correlates with the world outside the text and thus to assign to the text a certain degree of text coherence. Since the writer of a text is also one of its readers, the writer establishes coherence by adjusting the meaning contents of the terms he uses to his understanding of the realities they refer to. This, as explained above, may lead to polysemy. Secondly, the term's linear structure allows for the construction of a semantic edifice within the text through the creation of cohesive ties, which strengthen the overall unity of the text. These cohesive ties generally link the term to a lexical substitute (a synonym or a hyperonym) or to a grammatical substitute (usually a pronoun). However, the many terms which exhibit syntactic transparency participate, in addition, in a word-recurrence pattern which is less typical: a word-recurrence pattern that creates cohesion by linking a term to one or more of its alternate forms, forms of which one or more constituents have been zeroed.

These observations can now be used to define the term. The term is:

- A semantically charged linear structure, which names an abstract or a concrete reality studied by a special-subject field;

- When used in a special text, it plays a dynamic and important part in the bringing about of text coherence and of text cohesion;

- This contribution to text coherence and to text cohesion may translate into variability both on the level of its meaning content and of its linear structure, especially if its linear structure is syntactically transparent;

- This variability may lead to polysemy on the one hand, and signals on the other hand that terms exhibiting syntactic transparency are, in fact, paradigms, i.e. sets of all the possible forms the linear structure can have in a text.

\section{Conclusion}

The definition proposed above is a first attempt to describe the term and its behaviour in texts for specific purposes within the framework of text linguistics. As any first attempt, it possesses in all likelihood imperfections, which will have to be addressed in future. However, even as a draft that will need to be refined, it accomplishes what traditional terminology 
could not. Indeed, it accounts for what one observes when one adopts a corpus-based and thus, in fact, a semasiological approach to the compilation and to the description of terms: the variability of the term's meaning content as well as of its linear structure in subject-oriented texts.

\section{Bibliography}

Beaugrande, R.-A. de \& W. U. Dressler (1986). Introduction to Text Linguistics. London/New York: Longman.

Bleazard, G. B. (1985). Introducing Satellite Communications. Manchester: NCC Publications.

Bostian, C. W. \& T. Pratt (1986). Satellite Communications. New York: John Wiley.

Boulanger, J.-C. (1995). "Présentation: images et parcours de la socioterminologie." Meta 40(2), 194-205.

Bourigault, D. \& M. Slodzian (1999). "Pour une terminologie textuelle." Terminologies nouvelles 19, 29-32.

Bowker, L. (1998). "Variant Terminology: Frivolity or Necessity." T. Fontenelle et al. (eds) (1998). EURALEX'98 Proceedings. Liège: Université de Liège, 487-496.

Cajolet-Laganière, H. \& P. Martel (1994). "Caractéristiques lexicales des textes scientifiques: premières analyses.” P. Martel \& J. Maurais (dir.) (1994). Langues et sociétés en contact. Mélanges offerts à Jean-Claude Corbeil. Tübingen: Max Niemeyer, 269-282.

Collet, T. (2000). La réduction des unités terminologiques complexes de type syntagmatique. Thèse de doctorat. Université de Montréal.

Collet, T. (2003). "A Two-level Grammar of the Reduction Processes of French Complex Terms in Discourse." Terminology 9(1), 1-27.

Collet, T. (2004). "The Inclusion in a Technical Dictionary of Linguistic Information about Lexical Cohesion Phenomena in French Texts for Specific Purposes." G. Williams et al. (eds) (2004). EURALEX 2004 Proceedings. Lorient: Université de Bretagne-Sud, 537-545.

Di Sciullo, A. \& E. Williams (1987). On the Definition of Word, Cambridge/London: The MIT Press.

Eikmeyer, H. J. \& H. Rieser (1981). Words, Worlds and Contexts. Berlin/New York: de Gruyter.

Elbert, B. R. (1987). Introduction to Satellite Communication. Boston/London: Artech House.

Felber, H. (1984). Terminology Manual. Vienna: Infoterm.

Gutwinski, W. (1976). Cohesion in Literary Texts. A Study of Some Grammatical and Lexical Features of English Discourse. The Hague/Paris: Mouton.

Harris, Z. (1982). "Discourse and Sublanguage." R. Kittredge \& J. Lehrberger (eds) (1982). Sublanguage. Studies of Language in Restricted Semantic Domains. Berlin/New York: de Gruyter, 231-236.

Harris, Z. (1991). A Theory of Language and Information. A Mathematical Approach. Oxford: Clarendon Press.

Hoffmann, L. (1987). "Language for Special/Specific Purposes." U. Ammon, N. Dittmar \& K. J. Mattheier (eds) (1987). Sociolinguistics. An International Handbook of the Science of Language and Society. Berlin/New York: de Gruyter, 298-302. 
Lauriston, A. \& J. Le Néal (1985). Dictionnaire bilingue des télécommunications internationales 2. Montréal: Teleglobe Canada.

Lotte, D. S. (1981). "Principes d'établissement d'une terminologie scientifique et technique." V. I. Siforov (dir.) (1981). Textes choisis de terminologie. I. Fondements théoriques de la terminologie. Québec: GIRSTERM, 3-53.

Lundquist, L. (1989). “Coherence in Scientific Texts.” W. Heydrich et al. (eds) (1989). Connexity and Coherence - Analysis of Text and Discourse. Berlin/New York: de Gruyter, 122-149.

Petöfi, J. S. (1983). "Text, Signification, Models and Correlates: Some Aspects of Text Comprehension and Text Interpretation." G. Rickheit \& M. Bock (eds) (1983). Psycholinguistic Studies in Language Processing. Berlin/ New York: de Gruyter, 266-298.

Sager, J. C. (1990). A Practical Course in Terminology Processing. Amsterdam/ Philadelphia: John Benjamins.

Schröder, H. (1991). "Linguistic and Text-theoretical Research on Languages for Special Purposes." H. Schröder (ed.) (1991). Subject-oriented Texts. Languages for Special Purposes and Text Theory. Berlin/New York: de Gruyter, 1-48.

Temmerman, R. (1997). "Questioning the Univocity Ideal. The Difference Between Socio-cognitive Terminology and Traditional Terminology." Hermes $18,51-90$.

Temmerman, R. (2000). Towards New Ways of Terminology Description. The Sociocognitive Approach. Amsterdam/Philadelphia: John Benjamins.

Wales, R. O. (ed.) (1981). ATS-6 Final Engineering Performance Report. Volume I - Program and Systems Summaries: Mechanical and Thermal Details. Washington, D. C.: NASA.

Wüster, E. (1979). Einführung in die allgemeine Terminologielehre und in die terminologische Lexikographie. UNESCO ALSED LSP Network. 
